\title{
Preparation and Characterization of a Novel Polysaccharide-Iron(III) Complex in Auricularia auricula Potentially Used as an Iron Supplement
}

\author{
Tong Liu $\mathbb{D}^{1},{ }^{1}$ Tingting Liu $\mathbb{D}^{\mathbb{1}}{ }^{1}$ Hongcheng Liu $\mathbb{D}^{1},{ }^{1}$ Hongxiu Fan $\mathbb{D}{ }^{1}$ Bingyu Chen $\mathbb{D}{ }^{1}{ }^{1}$ \\ Dawei Wang $\mathbb{D},{ }^{1}$ Yanrong Zhang $\mathbb{D}^{1},{ }^{1}$ and Fengjie Sun $\mathbb{D}^{2}$ \\ ${ }^{1}$ School of Food Science and Engineering, Jilin Agricultural University, Changchun, China \\ ${ }^{2}$ School of Science and Technology, Georgia Gwinnett College, Lawrenceville, GA, USA \\ Correspondence should be addressed to Yanrong Zhang; zhangyanrong0044@jlau.edu.cn and Fengjie Sun; fsun@ggc.edu
}

Received 6 April 2019; Accepted 16 May 2019; Published 11 June 2019

Academic Editor: Marco Scioscia

Copyright (c) 2019 Tong Liu et al. This is an open access article distributed under the Creative Commons Attribution License, which permits unrestricted use, distribution, and reproduction in any medium, provided the original work is properly cited.

Iron deficiency anemia has been a widespread disease. As an effective and stable iron supplement, the physiochemical properties of the polysaccharide iron complex have been widely studied. In this study, we characterized a novel polysaccharide-iron(III) complex extracted in an edible fungal species Auricularia auricular (AAPS-iron(III)). The highest iron content (28.40\%) in the AAPS-iron(III) complex was obtained under the optimized preparation conditions including an AAPS to $\mathrm{FeCl}_{3 .} 6 \mathrm{H}_{2} \mathrm{O}$ ratio of $2: 3(\mathrm{w} / \mathrm{w})$, a $\mathrm{pH}$ value of 8.0 in solution, a reaction temperature of $50^{\circ} \mathrm{C}$, and a reaction time of $3 \mathrm{~h}$. The physical and chemical properties of the AAPS-iron(III) complex were characterized by qualitative and quantitative analyses using scanning electron microscope, particle size distribution, thermogravimetric analyzer, Fourier transform infrared spectroscopy, circular dichroism, and ${ }^{1} \mathrm{H}$ nuclear magnetic resonance. Result showed that, although the iron was bound to the polysaccharide, it was released under artificial gastrointestinal conditions. The AAPS-iron(III) complex exhibited high stability (under 50-256 $6^{\circ}$ ) and water solubility. The AAPS-iron(III) complex also showed high antioxidant activity in vitro, demonstrating an additional health benefit over other typical nonantioxidant iron nutritional supplements. Furthermore, the AAPS-iron(III) complex showed high efficiency on the treatment of the iron deficiency anemia in the model rats. Therefore, the AAPS-iron(III) complex can be used as a nutritional fortifier to supply iron in industrial processing and to assist the treatment of iron deficiency anemia.

\section{Introduction}

Iron is one of the most important minerals in the human body. As an auxiliary factor of metabolisms and functions of the immune system, iron plays an important role in maintaining the normal functions of organisms [1]. The World Health Organization has reported that $46 \%$ of children of 514 years old and $48 \%$ of pregnant women worldwide have symptoms of anemia, most of which are caused by iron deficiency [2]. The main causes of iron deficiency anemia include insufficient intake of iron from the diet, poor absorption of iron, increased physiological demand for iron, and excessive loss of iron. To compensate for the iron deficiency, ferrous salts such as ferrous sulfate, iron fumarate, and ferrous gluconate are commonly used as oral iron supplements $[3,4]$.
However, long-term use of oral iron supplements may cause gastrointestinal side effects [5] and iron-induced oxidative stress [6]. Studies have also shown that the gastrointestinal side effects caused by the long-term use of therapeutic ferrous sulfate oral agents may include nausea, vomiting, abdominal pain, and constipation [7-10]. Therefore, it is imperative to develop new iron supplements without the side effects.

The interest of polysaccharides of natural origin has expanded into the areas of anticancer, antitumor, antioxidant, antiobesity, neuroprotective, antimicrobial, and antiinflammatory, with broadened fields of applications of these polysaccharides in food supplements, cosmetics, pharmaceuticals, and biomedical uses [11, 12]. Recent studies have documented polysaccharide-iron(III) complexes with high stability and increased bioavailability in comparison to those 
of currently commonly used oral iron supplement, e.g., ferrous sulfate [13]. Polysaccharide-iron complexes have been the most studied among all of the iron(III) complexes because they have high stability and water solubility, and more important, reduced side effects $[14,15]$. Polysaccharide-iron complexes have also been used as iron supplements for treatment of iron deficiency anemia because of their relatively high bioavailability and significant reduction of side effects, e.g., gastrointestinal discomfort and oxidative stress induced by a high concentration of iron(III) absorption, in comparison with those of traditional oral iron supplements [16].

Auricularia auricula is a type of black saprophytic fungus that grows on decayed wood. This species is also commonly known as "wood ear" or "ear fungus" in Chinese, which literally means "the ear of the wood," due to the shape of its body. As a medicinal and edible fungus, Auricularia auricula has been produced mainly in China but widely consumed for over 1000 years worldwide. Although the species Auricularia auricula is widely planted in China [17], a large amount of the products is wasted due to the oversupply on the market, making it easier and cheaper to obtain this species of fungus in comparison to other sources of complexing agents. The most abundant functional components in this species of fungus are Auricularia auricula polysaccharides, which have been served as antioxidants [18-20], anticoagulants [21, 22], antitumor agents [23, 24], and blood lipid reducers [25]. In our current study, Auricularia auricula polysaccharides have shown high levels of bioactivity and could be potentially used as ligands for iron(III) to promote its absorption in the digestive system, significantly increasing the value of Auricularia auricula in both industrial and medicinal areas.

In this study, we have prepared and characterized the physicochemical properties of a novel polysaccharide iron(III) complex in Auricularia auricular (AAPS-iron(III)) using scanning electron microscope (SEM), thermogravimetric analyzer, Fourier transform infrared spectroscopy (FTIR), circular dichroism (CD), and ${ }^{1} \mathrm{H}$ nuclear magnetic resonance ( ${ }^{1} \mathrm{H}$ NMR). The bioavailability and antioxidant activity of the AAPS-iron(III) complex were studied by various in vitro assays. We have also focused on optimizing the preparation conditions of this complex.

\section{Materials and Methods}

2.1. Materials and Chemicals. Samples of Auricularia auricula were obtained from The Engineering Research Centre of Chinese Ministry of Education for Edible and Medicinal Fungi (Changchun, China).1,1-diphenyl-2-picrylhydrazyl (DPPH) and 2,2'-azino-bis-(3-ethylbenzthiazoline-6-sulfonic) (ABTS) were purchased from Sigma Chemical Co. (St. Louis, MO, USA). All other analytical grade chemical reagents were purchased from the Beijing Chemical Reagent Factory, China.

2.2. Purification of the Auricularia auricula Polysaccharide (AAPS). Polysaccharides of Auricularia auricula were obtained from the fungus using ultrasonic microwave (240W) together with hot water $\left(85^{\circ} \mathrm{C}\right)$ extraction, protein and pigment removal with macroporous resin method, and alcohol
$(80 \% \mathrm{v} / \mathrm{v})$ precipitation. The extraction yield was $21.25 \%$ and the polysaccharide content of the sample was $70.58 \%$. As the main fractions, AAPS was isolated from the sample by diethylaminoethyl (DEAE) cellulose-52 chromatography and Sephadex G-100 gel filtration chromatography. The final yield of AAPS was $42.86 \%$ with the polysaccharide content of $95.35 \%$. The monosaccharide composition of the AAPS was determined by the precolumn derivatization of High Performance Liquid Chromatography (HPLC) as an acidic heteropolysaccharide, mainly composed of mannose, glucuronic acid, glucose, and xylose with the molar ratio of 3.62:7.23:12.57:4.24 and the relative molecular weight of 3.783 $\times 105 \mathrm{Da}$.

2.3. Preparation of the AAPS-Iron(III) Complex. The AAPSiron(III) complex was prepared and characterized according to a modified method of Dong et al. [26]. The AAPSiron(III) complex was formed by neutralization of an $\mathrm{FeCl}_{3}$ carbohydrate solution. Briefly, $0.3 \mathrm{~mL}$ of $\mathrm{FeCl}_{3} \cdot 6 \mathrm{H}_{2} \mathrm{O}(2 \mathrm{M})$ was added dropwise with continuous stirring to an aqueous solution containing 2\% (w:w) of AAPS and 1.5\% (w:w) of sodium citrate. The $\mathrm{pH}$ was adjusted to $6.0,7.0,8.0,9.0$, and 10.0 , respectively, by adding either $\mathrm{HCl}(2 \mathrm{M})$ or $\mathrm{NaOH}(2$ $\mathrm{M})$. The temperature was set at $30^{\circ} \mathrm{C}, 40^{\circ} \mathrm{C}, 50^{\circ} \mathrm{C}, 60^{\circ} \mathrm{C}$, and $70^{\circ} \mathrm{C}$, respectively, using a constant temperature oscillation incubator. After 3, 4, 5, 6, 7, 8, and $9 \mathrm{~h}$, respectively, the reaction mixture was centrifuged at $4000 \times g$ for $10 \mathrm{~min}$. The supernatant was concentrated and subsequently dialyzed in distilled water to remove the unbound ions. The retentate was condensed and the solid portions were precipitated using anhydrous ethanol and then freeze-dried for further experiments.

2.4. Qualitative Identification of AAPS-Iron(III) Complex. Ten milligrams of dried AAPS-iron(III) complex was dispersed in $2 \mathrm{~mL}$ of $\mathrm{H}_{2} \mathrm{O}$ and the resulting mixture was stirred at room temperature for $2 \mathrm{~h}$. A few drops of potassium thiocyanate were then added to the solution and the reaction phenomenon was observed and recorded. In a similar manner, $10 \mathrm{mg}$ of dried AAPS-iron(III) complex was dispersed in $2 \mathrm{~mL}$ of $\mathrm{HCl}(1 \mathrm{M})$ and stirred at room temperature for $2 \mathrm{~h}$. A few drops of potassium ferrocyanide were then added and the reaction phenomenon was observed and recorded.

2.5. Quantification of Iron Content. Quantification of the iron content was performed according to the method of Pitarresi et al. [27] with minor modifications. Ten milligrams of dried AAPS or AAPS-iron(III) complex was dispersed in $20 \mathrm{~mL}$ of $\mathrm{HCl}(1 \mathrm{M})$ by stirring for $24 \mathrm{~h}$ in order to break the compounds to release the iron. Then, mix $1 \mathrm{~mL}$ of each solution with $1 \mathrm{~mL}$ of hydroxylamine hydrochloride (10\%), $2.5 \mathrm{~mL}$ 1,10-phenanthroline (10\%), and $5 \mathrm{~mL}$ sodium acetate trihydrate buffer solution ( $\mathrm{pH} 4.5)$. The mixed solution was subjected to UV-vis analysis (UV-2450 spectrophotometer, Shimadzu, Japan). The iron content in the AAPS-iron(III) complex was calculated from the absorbance at $510 \mathrm{~nm}$. The calibration curve was obtained by using the standard solutions of ferrous ammonium sulfate in distilled water based on the following formulate: $y=0.0045 x-0.170$, where 
$\mathrm{y}$ is the absorbance at $510 \mathrm{~nm}$ and $\mathrm{x}$ is the content of iron $\left(\mathrm{R}^{2}\right.$ $=0.9995)$.

\subsection{Physicochemical Characterization of the AAPS-Iron(III) Complex}

2.6.1. SEM Analysis. The powdered AAPS or AAPS-iron(III) complex was observed using an environmental scanning electron microscope (SSX-550, Shimadzu, Japan). Samples were evenly dispersed on a sample stage covered with a double-sided adhesive and sprayed with gold powder. The accelerated voltage was set to $5.0 \mathrm{kV}$ and each sample was observed at $500 \times$ and $20,000 \times$ magnifications.

2.6.2. Particle Size Distribution and Molecular Weight Analysis. AAPS and the AAPS-iron(III) complex were each dispersed in ultrapure water to make the solutions $(2 \%$ $\mathrm{g} / \mathrm{ml}$ ). The particle size distributions of the samples were determined by a laser particle size analyzer (Mastersizer3000, Malvern Instruments Ltd, United Kingdom) with a shading rate of $10-20 \%$ and scattering intensity of 35 . The relative molecular weights of AAPS and AAPS-iron(III) complex were estimated on an Agilent 1100 HPLC system equipped with a refractive index detector (RID) and a PL aquagel-OH Column (79911GF-083, Agilent). The sample was filtered on a $0.45-\mu \mathrm{m}$ pore membrane before injection $(20 \mu \mathrm{L})$ and eluted with $\mathrm{Na}_{2} \mathrm{SO}_{4}$ solution $(0.1 \mathrm{M})$ in PBS buffer $(0.01 \mathrm{M}, \mathrm{pH}$ 6.8) at a flow rate of $0.7 \mathrm{~mL} / \mathrm{min}$. The column temperature was maintained at $40^{\circ} \mathrm{C}$.

2.6.3. Thermogravimetric Analysis (TGA). The desired sample $(5 \mathrm{mg})$ was placed on an aluminum sample plate of the thermogravimetric analyzer (TGA4000, PerkinElmer, USA). Nitrogen $(99.99 \%$ ) with a flow rate of $30 \mathrm{~mL} / \mathrm{min}$ was used as a carrier gas. The detection temperature was raised from $50^{\circ} \mathrm{C}$ to $650^{\circ} \mathrm{C}$ at a heating rate of $10^{\circ} \mathrm{C} / \mathrm{min}$.

\subsection{Spectroscopic Characterization of \\ the AAPS-Iron(III) Complex}

2.7.1. Fourier Transform Infrared Spectroscopy (FTIR) Analysis. Infrared spectral analysis was performed using an FTIR spectrometer (IR Prestige-21, Shimadzu, Japan). Two milligrams of AAPS or the AAPS-iron(III) complex was dried with $200 \mathrm{mg}$ potassium bromide at $105^{\circ} \mathrm{C}$, mixed uniformly, and compacted into a disk for the collection of infrared spectra at $4000-400 \mathrm{~cm}^{-1}$. The spectra were recorded with a resolution of $4 \mathrm{~cm}^{-1}$ and a coaddition of 16 scans and were analyzed using IRSolution (Shimadzu Optics Limited, Japan).

2.7.2. Circular Dichroism (CD) Analysis. The CD spectra of AAPS and the AAPS-iron(III) complex solutions (1.0 $\mathrm{mg} / \mathrm{mL}$ ) were measured on a J-820CD spectropolarimeter (JASCO, Japan). Each CD spectrum represented the accumulation of three scans at $100 \mathrm{~nm} / \mathrm{min}$ with a time constant of 1 $\mathrm{s}$ and a slit width of $1 \mathrm{~nm}$. Data were collected from 185 to 300 $\mathrm{nm}$ with an interval of $1 \mathrm{~nm}$.
2.7.3. ${ }^{1} \mathrm{H}$ Nuclear Magnetic $\left({ }^{1} \mathrm{H}\right.$ NMR) Analysis. The ${ }^{1} \mathrm{H}$ NMR spectra of AAPS and the AAPS-iron(III) complex were recorded in pure $\mathrm{D}_{2} \mathrm{O}$ (Cambridge Isotope Laboratory, Inc., USA) and at room temperature using a Bruker Advance 600 MHz NMR spectrometer (Bruker, Germany). 500 and 1000 scans were used for AAPS and the AAPS-iron(III) complex, respectively.

2.8. Iron Release In Vitro Assay of the AAPS-Iron(III) Complex. Artificial gastric juice was prepared according to Hasan et al. [28]. Sodium chloride $(2.0 \mathrm{~g})$ and pepsin $(3.2 \mathrm{~g})$ were dissolved in quadruple-distilled water. After adding $80 \mathrm{~mL}$ of $1 \mathrm{M} \mathrm{HCl}$, additional quadruple-distilled water was added to obtain the final volume of $1000 \mathrm{~mL}(\mathrm{pH} \mathrm{2.0)}$. Artificial intestinal juice ( $\mathrm{pH} 8.0$ ) was prepared by dissolving $5.0 \mathrm{~mL}$ each of bile salt mixture $(25.0 \mathrm{~g} / \mathrm{L})$ and pancreatic extract $(4.0 \mathrm{~g} / \mathrm{L})$ in $\mathrm{NaHCO}_{3}(1 \mathrm{M})$, followed by adding quadrupledistilled water to reach the final volume of $1000 \mathrm{~mL}$ [29]. Iron release from the AAPS-iron(III) complex was measured according to the modified method of AlKhatib et al. [30]. Two types of dissolution media were used during the two successive stages of iron release. First, $50 \mathrm{mg}$ of the AAPSiron(III) complex was pulverized and placed in a 500-ml flask for $2 \mathrm{~h}$ with the artificial gastric juice ( $\mathrm{pH} 2.0$ ). Then, the solids were removed from the artificial gastric juice and, without cleaning, placed in a flask containing $500 \mathrm{~mL}$ of the artificial intestinal juice $(\mathrm{pH} 8.0)$ for $3 \mathrm{~h}$. The dissolution media were maintained at $37^{\circ} \mathrm{C}$ throughout the process. Samples (10 $\mathrm{mL}$ ) were withdrawn at predetermined time intervals for analysis of the iron ions released. The withdrawn volumes were immediately replaced by the equivalent volumes of fresh medium to maintain the overall volume. The sample solution was filtered through a $0.45-\mu \mathrm{m}$ pore membrane and analyzed using the method of Pitarresi et al. [27] on 2,5-phenanthroline to calculate the amount of iron released.

\subsection{Antioxidant Activities of the AAPS-Iron(III) Complex}

2.9.1. DPPH Radical Scavenging Activity. The DPPH radical scavenging activity was determined according to the methods of Chen et al. [31] and Zhang et al. [32] with minor modifications. A DPPH solution $(2 \mathrm{mmol} / \mathrm{L})$ was prepared in anhydrous ethanol in advance. A sample $(1.0 \mathrm{~mL})$ of the AAPS-iron(III) complex in distilled water (at a series of concentrations of $0.0,0.1,0.2,0.3,0.4,0.5,0.6,0.7,0.8,0.9$, and $1.0 \mathrm{mg} / \mathrm{mL}$ ) was added to $1.6 \mathrm{~mL}$ of distilled water and $0.4 \mathrm{~mL}$ of DPPH solution $(2 \mathrm{mM})$. The mixture was shaken in a water bath $\left(30^{\circ} \mathrm{C}\right)$ under dim light and incubated for $10 \mathrm{~min}$. Deionized water was used as the blank control sample and ascorbic acid as the positive control sample. The absorbance of the reaction system was measured at $517 \mathrm{~nm}$. The DPPH radical scavenging activity was assessed using the following equation: DPPH radical scavenging ability $(\%)=\left[1-\left(\mathrm{A}_{1}-\mathrm{A}_{2}\right) / \mathrm{A}_{0}\right] * 100$, where $A_{1}$ is the absorbance of the sample or ascorbic acid with the DPPH solution, $A_{2}$ is the absorbance of the mixture with deionized water, and $\mathrm{A}_{0}$ is the absorbance of the blank control. 
2.9.2. ABTS Radical Scavenging Activity. The ABTS radical scavenging activity was evaluated according to the method of Liang et al. [33] with some modifications. ABTS (0.3841 g) and $\mathrm{K}_{2} \mathrm{~S}_{2} \mathrm{O}_{8}(0.0662 \mathrm{~g})$ were dissolved in deionized water and the resulting solution was transferred to a $100-\mathrm{mL}$ volumetric flask and diluted with deionized water to a final volume of $100 \mathrm{~mL}$. The mixture was then incubated in dark for 12 to $16 \mathrm{~h}$ at room temperature. A stock solution of ABTS (7.0 $\mathrm{mmol} / \mathrm{L})$ and $2.45 \mathrm{~K}_{2} \mathrm{~S}_{2} \mathrm{O}_{8}(2.45 \mathrm{mmol} / \mathrm{L})$ was diluted with PBS $(0.01 \mathrm{~mol} / \mathrm{L}, \mathrm{pH} 7.4)$ to a concentration that provided an absorbance of 0.7 at $734 \mathrm{~nm}$. In the reaction system, 1.0 $\mathrm{mL}$ of $\mathrm{H}_{2} \mathrm{O}$ and $2.0 \mathrm{~mL}$ of the ABTS solution were added to $1.0 \mathrm{~mL}$ of the sample solution of AAPS, AAPS-iron(III) complex, or ascorbic acid in distilled water to make a series of concentrations of $0,0.1,0.2,0.3,0.4,0.5,0.6,0.7,0.8,0.9$, and $1.0 \mathrm{mg} / \mathrm{mL}$, respectively. Each solution was shaken well and placed in dark for $6 \mathrm{~min}$ at room temperature, and then the absorbance of the mixture was measured at $734 \mathrm{~nm}$. Deionized water was used as the blank control and ascorbic acid as the positive control. The ABTS radical scavenging activity was calculated based on the following equation: ABTS radical scavenging ability $(\%)=\left[1-\left(\mathrm{A}_{1}-\mathrm{A}_{2}\right) / \mathrm{A}_{0}\right] * 100$, where $\mathrm{A}_{1}$ is the absorbance of the sample solution or ascorbic acid with ABTS, $A_{2}$ is the absorbance of the sample solution or ascorbic acid with deionized water, and $\mathrm{A}_{0}$ is the absorbance of the blank control.

2.9.3. Inhibition Assay of Liver Lipid Peroxidation. Inhibition of lipid peroxidation in livers of Kunming rats (weighed 18-20 $\mathrm{g}$, provided by the Changchun Institute of Biological Products Co., Ltd., Changchun, China) was evaluated according to the method of $\mathrm{Ma}$ et al. [34] with some modifications. Rats were sacrificed and the livers were rapidly washed and homogenized at $4^{\circ} \mathrm{C}$ in a volume of normal saline that was 25 times the amount of the volume of the livers. One milliliter of sample solution of AAPS, AAPS-iron(III) complex, or ascorbic acid (with a series of concentrations of $0,0.1,0.2,0.3$, $0.4,0.5,0.6,0.7,0.8,0.9$, and $1.0 \mathrm{mg} / \mathrm{mL}$ in distilled water) was mixed separately with $1.0 \mathrm{~mL}$ of mouse liver homogenate, 0.1 $\mathrm{mL}$ of $\mathrm{FeSO}_{4}(6 \mathrm{mM})$, and $0.05 \mathrm{~mL}$ of $\mathrm{H}_{2} \mathrm{O}_{2}(60 \mathrm{mM})$, and the mixtures were incubated at $37^{\circ} \mathrm{C}$ for $1.5 \mathrm{~h}$. Each mixture was added to $1.0 \mathrm{~mL}$ of trichloroacetic acid solution $(10 \%$, $\mathrm{w} / \mathrm{v})$ and $1.0 \mathrm{~mL}$ thiobarbituric acid solution $(0.67 \%, \mathrm{w} / \mathrm{v})$, mixed and boiled for $15 \mathrm{~min}$, and then cooled with water. After centrifugation at $4000 \mathrm{rpm}$ for $5 \mathrm{~min}$, the absorbance of the supernatant was measured at $532 \mathrm{~nm}$ using deionized water as a blank control. Malondialdehyde (MDA) is an aldehyde-based by-product produced by lipid peroxidation which causes strong chemical toxicity to cells. Therefore, MDA production is used as an indicator of the level of lipid peroxidation [35]. The inhibition ratio of MDA was calculated according to the following equation: inhibition ratio of $\operatorname{MDA}(\%)=\left[1-\left(\mathrm{A}_{1}-\mathrm{A}_{2}\right) / \mathrm{A}_{0}\right] * 100$, where $\mathrm{A}_{1}$ is the absorbance of the mixture with the sample solution or ascorbic acid, $A_{2}$ is the absorbance of the sample solution with deionized water, and $\mathrm{A}_{0}$ is the absorbance of the blank control.

2.10. Antianemia Function Test of the AAPS-Iron(III) Complex. The rat model of iron deficiency anemia was established according to Yun et al. [36] with minor modifications. Sixty Wistar rats (30 males and 30 females, 6-8 weeks old, weighed $200 \pm 20$ g, provided by the Changchun Institute of Biological Products Co., Ltd., Changchun, China) were fed adaptively for three days prior to the measurements of the blood parameters using a Hitachi 7080 automatic biochemical analyzer (Hitachi, Japan). The number of red blood cells (RBC), hemoglobin (HB), mean corpuscular volume (MCV), mean hemoglobin content $(\mathrm{MCH})$, and red blood cell volume distribution width (RDW) were measured as normal values prior to the model establishment. The 60 rats were randomly divided into two groups: 10 rats were fed with basic diet as blank control (BC) group and the other 50 rats (the treatment group) were fed with low iron diet for four weeks and blood samples were collected from tail vein twice a week for 8 times. Both groups were fed with free water. Stainless steel cages are used to keep the rats in order to prevent iron pollution. In four weeks, RBC, $\mathrm{HB}, \mathrm{MCV}, \mathrm{MCH}$, and $\mathrm{RDW}$ were measured by sampling the blood from the tail vein. A model rat is considered successful if the value of HB is less than $100 \mathrm{~g} / \mathrm{L}$.

2.10.1. Animal Grouping and Treatment. The 60 model rats of iron deficiency anemia were randomly divided into five groups based on the amount of AAPS-iron(III) complex in their diet: model control group (MC), positive control group (PC), high dose group (HI), medium dose group (MI), and low dose group (LW). The PC group was fed with ferrous sulfate $(8.3 \mathrm{mg} / \mathrm{kg})$. The HI, MI, and LW groups were fed with AAPS-iron(III) complex of $16.4 \mathrm{mg} / \mathrm{kg}, 8.2 \mathrm{mg} / \mathrm{kg}$, and $4.1 \mathrm{mg} / \mathrm{kg}$, respectively. Except for the BC group, other five groups continued to be fed with low iron diet. All animals were given the tested drugs based on the intragastric volume of $10 \mathrm{ml} / \mathrm{kg}$. The $\mathrm{BC}$ and $\mathrm{MC}$ groups were given distilled water of the same volume once a day for five weeks. Once the experiments started, the general observations of the animals were made. The body weight of the animals was measured every 7 days and the state of the animals was observed. Five weeks after administration, abdominal aorta blood samples were collected at $3500 \mathrm{r} / \mathrm{min}$ to determine the contents of erythrocyte free protoporphyrin (FP), HB, RBC, Hematocrit (HCT), MCV, MCH, and the mean corpuscular hemoglobin concentration $(\mathrm{MCHC})$ in erythrocyte.

2.11. Statistical Analysis. All experiments were repeated three times. The results were shown as average \pm standard deviation. SPSS (version 18.0, IBM Corp., Armonk, NY, USA) was used to perform the one-way analysis of variance (ANOVA) and the least significance difference (LSD) Duncan analysis. A statistically significant difference is indicated by $\mathrm{p}<0.05$ or $\mathrm{p}<0.01$.

\section{Results and Discussion}

\subsection{Physicochemical Characterization of the AAPS-Iron(III) Complex}

3.1.1. Preparation of the AAPS-Iron(III) Complex. Morphological observations showed that both AAPS and the AAPSiron(III) complex were odorless, while AAPS was white 


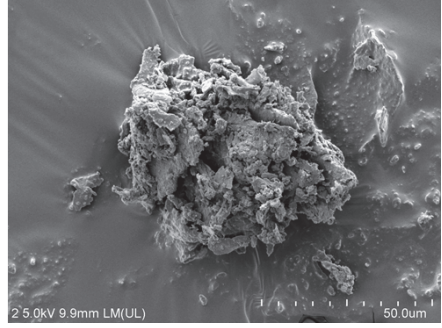

(a)

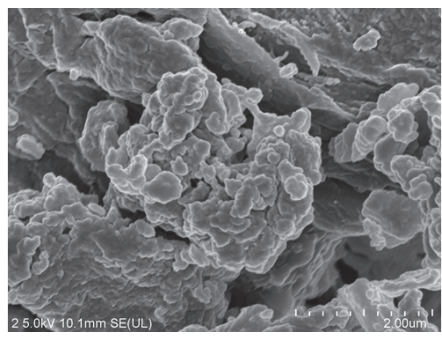

(c)

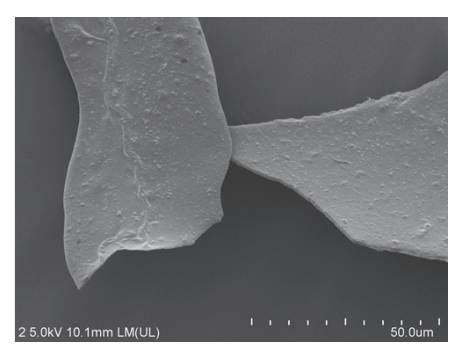

(b)

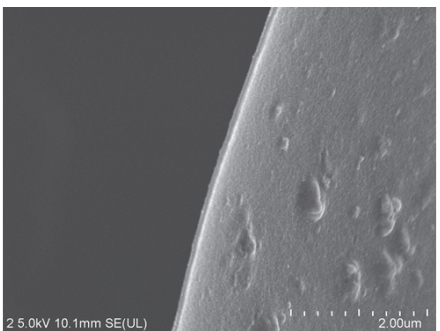

(d)

FIGURE 1: SEM images of AAPS ((a) and (c)) and the AAPS-iron(III) complex ((b) and (d)) with a sample thickness of about $0.1 \mu$ m. $500 \times$ magnification in (a) and (b); 20,000× in (c) and (d).

granular power and the AAPS-iron(III) complex was reddish brown amorphous powder. The preparation of the AAPSiron(III) complex has been previously reported in Astragalus membranaceus [37]. Under weak alkaline conditions, the iron ions polymerize through an oxygen bridge or a hydroxyl bridge. Citric acid is then released during the polymerization of the ferric citrate. Under alkaline conditions, polysaccharides interact with iron on the surface of the polymerized ferric citrate to form the polysaccharide-iron complex. In our study, results showed that, after adding ferric chloride to the solution of Auricularia auricula polysaccharides with sodium citrate, iron ions react with citrate ions to form a ferric citrate complex. The reaction system is kept in an alkaline environment through dropwise addition of sodium hydroxide solution throughout the experiments. The optimum preparation conditions of the AAPS-iron(III) complex included a ratio of AAPS to $\mathrm{FeCl}_{3} \bullet 6 \mathrm{H}_{2} \mathrm{O}$ of $2: 3$ (w/w), $\mathrm{pH}$ 8.0 , reaction temperature of $50^{\circ} \mathrm{C}$, and reaction time of 3 h. The AAPS-iron(III) complex had a relatively high iron content $(28.40 \%)$ compared to those previously reported and showed increased water solubility. For example, Xu et al. [13] have obtained iron content of $24.15 \%$ in the AAPSiron(III) complex in a fungal species of Grifola frondosa under the optimum preparation conditions based on the single factor and orthogonal optimization experiments, including a ratio of AAPS to the catalyst (sodium citrate) of 1:1 (g/g), reaction temperature of $80^{\circ} \mathrm{C}$, reaction time of $1.5 \mathrm{~h}$, and $\mathrm{pH}$ 8.0 .

3.1.2. Qualitative Identification of the AAPS-Iron(III) Complex. When drops of potassium ferrocyanide or potassium thiocyanate reagents were added to an aqueous solution of the AAPS-iron(III) complex, the appearance of the aqueous solution did not change (data not shown). In contrast, when potassium ferrocyanide or potassium thiocyanate was added to the AAPS-iron(III) complex in a hydrochloric acid solution, a dark blue precipitate and a blood red flocculent appeared, respectively (data not shown). These results clearly show that the AAPS-iron(III) complex does not contain free iron ions and the polysaccharide and iron were bonded rather than simply physically mixing together. The bond between the polysaccharide and iron was broken by strong acid to release the iron ions, resulting in the qualitative identification of the AAPS-iron(III) complex.

3.1.3. SEM Analysis. Microphotographs showed that the morphologies of the fragmented AAPS and AAPS-iron(III) complex granules are very different (Figure 1). The polysaccharide of AAPS is flocculent with a rough surface (Figures 1(a) and $1(\mathrm{c})$ ), while the AAPS-iron(III) complex shows a sheetlike structure with a smooth surface and neat edges (Figures 1(b) and $1(\mathrm{~d})$ ). These morphological observations may be due to the interactions of the polysaccharides with iron, changing the internal structure of the polysaccharides and subsequently their morphological appearances. Similar SEM observations have also been reported in the increased surface in the AAPS-iron(III) complex in Astragalus membranaceus [37].

3.1.4. Particle Size Distribution and Molecular Weight Anal$y$ sis. The particle size distribution index $\mathrm{D}_{50}$ values were $18 \mu \mathrm{m}$ and $96 \mu \mathrm{m}$ for AAPS and AAPS-iron(III), respectively (Figure 2). The average molecular weights of AAPS and AAPS-iron(III) complex were estimated to be 3.783 


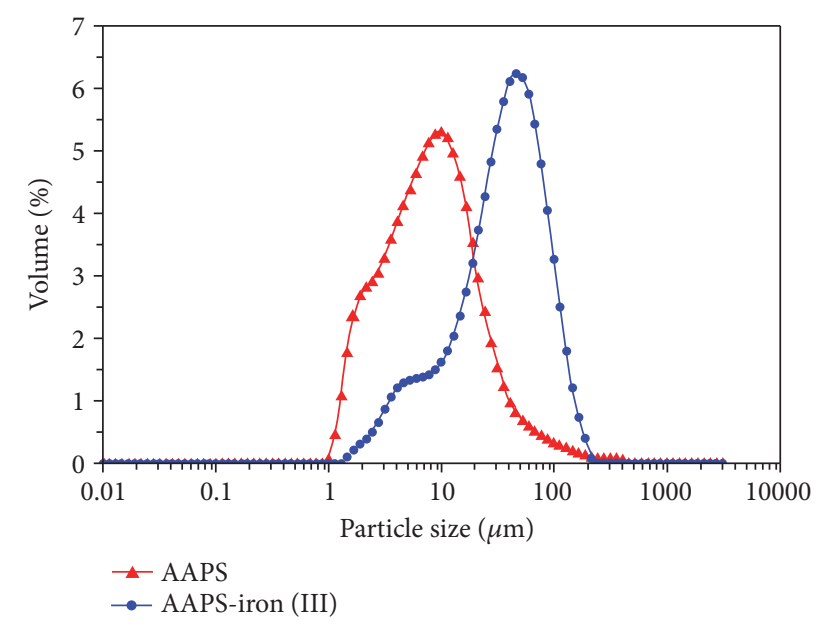

FIgUre 2: Particle size distribution of AAPS and the AAPS-iron(III) complex.

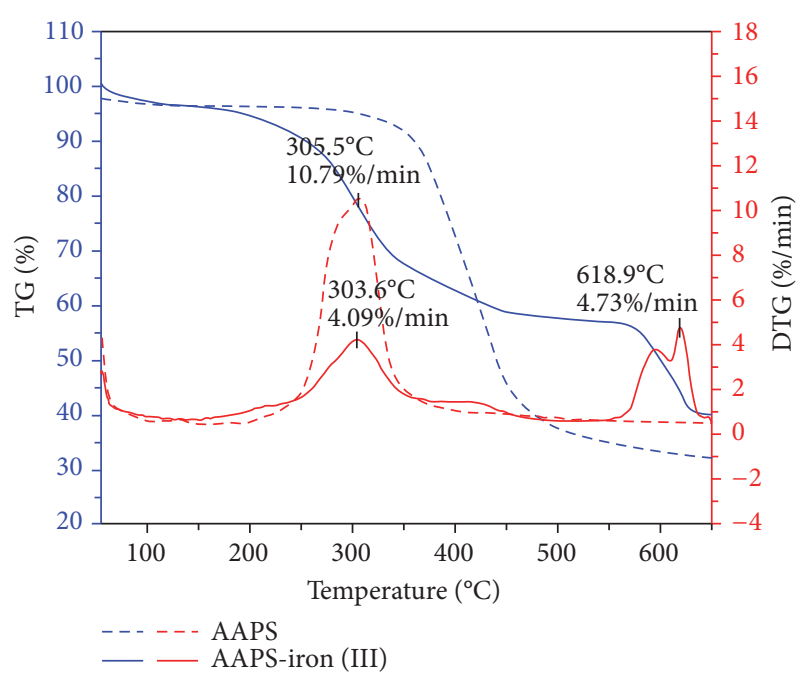

FIgURE 3: Thermogravimetry (TG) and derivative thermogravimetry (DTG) curves of AAPS and the AAPS-iron(III) complex.

$\times 10^{5} \mathrm{Da}$ and $8.708 \times 10^{5} \mathrm{Da}$, respectively. The particle sizes and average molecular weights of the AAPSiron(III) complex were significantly larger than those of AAPS (Figure 2), which was also observed in the SEM analysis (Figure 1). These results could be explained by the structural change of polysaccharide caused by its complexation with iron, resulting in significant differences in the particle size between AAPS and the AAPS-iron(III) complex. Comparable particle size distribution index $\mathrm{D}_{50}$ values of AAPS and AAPS-iron(III) complex $(20 \mu \mathrm{m}$ and $104 \mu \mathrm{m}$, respectively) were also reported in Inonotus obliquus [38].

3.1.5. Thermogravimetric Analysis (TGA). The thermal stabilities of AAPS and the AAPS-iron(III) complex were investigated by thermogravimetric analysis (Figure 3 ). As previously reported [39], thermogravimetry (TG) curve was used to reflect the relationships between the sample weight and temperature, while the derivative thermogravimetry (DTG) curve was used to describe the relationships between the temperature and the rate of material weight changes upon heating. In our study, when temperatures increased from $50^{\circ} \mathrm{C}$ to $265^{\circ} \mathrm{C}$, the mass loss of AAPS was primarily the free water and the rate of weight loss was $95.7 \%$. AAPS decomposed drastically from 265 to $\sim 500^{\circ} \mathrm{C}$. For example, the rate of mass loss of AAPS reached $10.79 \%$ at $305.5^{\circ} \mathrm{C}$. The rates of mass loss of AAPS decreased and tended to be stable at temperatures higher than $550^{\circ} \mathrm{C}$. The final residual mass of AAPS was $28.8 \%$. From $50^{\circ} \mathrm{C}$ to $256^{\circ} \mathrm{C}$, the mass loss of the AAPS-iron(III) complex was the free water and the rate of weight loss was $94.6 \%$, comparable to that of AAPS. The AAPS-iron(III) complex underwent the first rapid thermal decomposition from 256 to $500^{\circ} \mathrm{C}$. At $303.6^{\circ} \mathrm{C}$, the rate of mass loss was $4.09 \% / \mathrm{min}$ and the rate of weight loss was $56.5 \%$. A second thermal decomposition of the AAPS-iron(III) complex, stronger than the first one, occurred from 574 to $635^{\circ} \mathrm{C}$. At $618.9^{\circ} \mathrm{C}$, the rate of mass loss of the AAPS-iron(III) complex was $4.73 \% / \mathrm{min}$, whereupon the rate of mass loss of the AAPS-iron(III) complex tended to decrease until the final residual mass reached $38.9 \%$. These results show that the residual mass of the AAPS-iron(III) complex was significantly higher than that of AAPS, likely due to the high content of iron in the AAPSiron(III) complex. Therefore, it is reasonable to speculate that the complexation of AAPS with iron ions causes the two thermal decompositions of the APPS-iron(III) complex. These results demonstrate that the AAPS-iron(III) complex maintained high thermal stability in the temperature ranging from $50^{\circ} \mathrm{C}$ to $256^{\circ} \mathrm{C}$, indicating that the AAPS-iron(III) complex is sufficiently stable if used as a type of nutritional fortifiers which are generally required to be stable below $250^{\circ} \mathrm{C}$ in the food industry. Similar thermal stability was also reported in Grifola frondosa [13], where the AAPS-iron(III) complex showed increased high stability in the temperature ranging from room temperature to $275^{\circ} \mathrm{C}$ in comparison to AAPS.

\subsection{Spectroscopic Characterization of the AAPS-Iron(III) Complex}

3.2.1. FTIR Analysis. The FTIR spectra of AAPS and the AAPS-iron(III) complex (Figure 4) showed that iron complexing did not significantly disrupt the structures of the functional groups in AAPS of the AAPS-iron(III) complex. Similarly, the results by Wang et al. [40] also showed the congruence between the infrared spectra of both the polysaccharide and the polysaccharide-chromium(III) complex in Inonotus obliquus, indicating that the structure of the polysaccharide was not destroyed in the polysaccharidechromium(III) complex. Based on these results, it is predicted that the structure (i.e., the functional groups) of the polysaccharide is not destroyed when complexing with the metal ion. The absorption peaks of AAPS and the AAPSiron(III) complex at $3400 \mathrm{~cm}^{-1}$ were previously assigned 


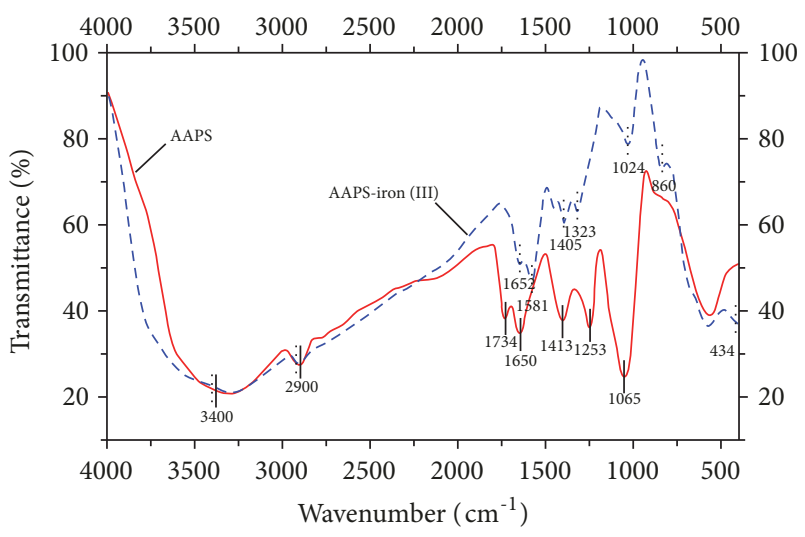

FIGURE 4: FTIR spectra of AAPS and the AAPS-iron(III) complex.

to $\mathrm{O}-\mathrm{H}$ stretching vibrations in Ulva pertusa [41], to C$\mathrm{H}$ stretching vibrations at $2900 \mathrm{~cm}^{-1}$ in pullulan [42], and to $\mathrm{C}=\mathrm{O}$ vibrations at peaks of $1734,1652,165$, and 1581 $\mathrm{cm}^{-1}$ in Qingzhuan brick tea [43]. These results indicated that free carboxyl and uronic acid may be present in the sample $[44,45]$. The absorption peaks of AAPS and the AAPS-iron(III) complex at 1413, 1405, 1323, 1253, 1065, and $1024 \mathrm{~cm}^{-1}$ were primarily $\mathrm{C}-\mathrm{O}$ and $\mathrm{C}-\mathrm{C}$ vibrations, as well as flexural vibrations of $\mathrm{C}-\mathrm{C}-\mathrm{H}$ and $\mathrm{C}-\mathrm{O}-\mathrm{H}$, indicating the existence of a pyran-ring structure [46]. In our study, evident changes in the shape of the peaks and the signal intensity of AAPS and the AAPS-iron(III) complex were observed in the range of $2000-800 \mathrm{~cm}^{-1}$ (Figure 4). These changes are likely due to the complexation of AAPS with iron ions under alkaline conditions. The absorption peaks at 860 and $434 \mathrm{~cm}^{-1}$ of the AAPS-iron(III) complex are considered as the characteristic absorption peaks of $\mathrm{FeOOH}$ [38]. In our study, weak absorption peak and no clear absorption peak were observed at 860 and $434 \mathrm{~cm}^{-1}$, respectively (Figure 4), indicating that the structure of the AAPS-iron(III) complex may be similar to that of $\mathrm{FeOOH}$.

3.2.2. CD Analysis. Circular dichroism spectroscopy is commonly used to detect two dimensional structures of biological macromolecules with optically active groups. Studies have shown that polysaccharides have strong absorption peaks in the far ultraviolet region, especially near $190 \mathrm{~nm}$ [47]. Furthermore, the polysaccharides exhibit folding, inversion, entanglement, and irregular morphology due to the interactions between molecules in aqueous solutions. Therefore, the molecular asymmetry occurs, leading to the Cotton effect, and the configuration of asymmetric sugars in solution can be analyzed by circular dichroism spectroscopy [48]. Our results of the circular dichroism chromatograms of AAPS and the AAPS-iron(III) complex showed (Figure 5) that, when the polysaccharide complexed with iron ions, the signal peaks at 190 and $196 \mathrm{~nm}$ shifted to 197 and $201 \mathrm{~nm}$, respectively, and the positive peak at $229 \mathrm{~nm}$ appeared at $239 \mathrm{~nm}$ with reduced signal intensity. It has been reported that metal ions react with carboxyl groups on sugars, resulting in the mutual polymerization of polysaccharide chains to form an "egg box"

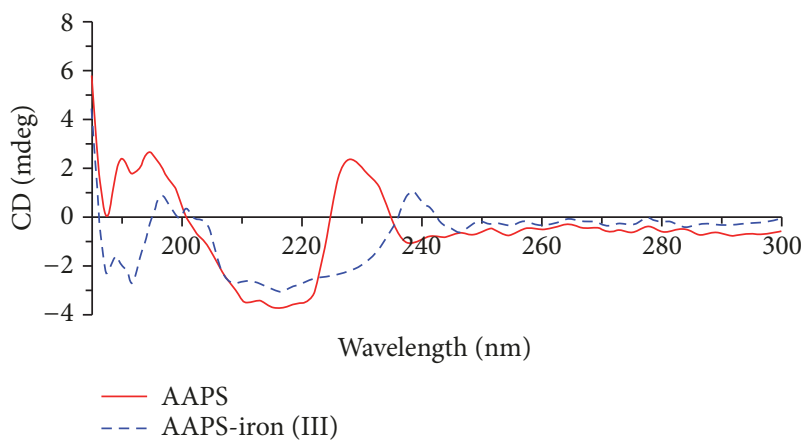

Figure 5: Circular dichroism spectra of AAPS and the AAPSiron(III) complex.

structure, which leads to increased molecular asymmetry and changes in molecular conformation [49]. Similar results have also been reported by Zhang et al. [50]. Significant shift was not detected between the positive and negative CD spectra of the polysaccharide and its complex with chromium(III) in Momordica charantia, indicating that the 3-dimensional spiral structure of the polysaccharide was not changed by the complexing with chromium(III). However, the structural asymmetry of the polysaccharide was enhanced by the formation of the polysaccharide-chromium(III) complex. Furthermore, our study shows that new negative peaks appeared at 187 and $192 \mathrm{~nm}$ (Figure 5), indicating that the conformation of the Auricularia auricula polysaccharides changed upon the complexation with iron ions. This is probably because the iron(III) ions are bound to the binding sites in the AAPS to form spatially separated iron centers on the polysaccharide backbone.

3.2.3. ${ }^{1} H$ NMR Analysis. In general, the absorption peaks of polysaccharides are mainly distributed in the region of $\delta 4.0$ $5.5 \mathrm{ppm}$ in the ${ }^{1} \mathrm{H}$ NMR spectrum, and more specifically, $\mathrm{H}-1$ is primarily distributed in the region of $\delta 4.8-5.5 \mathrm{ppm}$, and $\mathrm{H}-2$ and $\mathrm{H}-6$ in the region of $\delta 4.0-4.8 \mathrm{ppm}$ [51]. In our study, the ${ }^{1} \mathrm{H}$ NMR spectrum of AAPS (Figure $6(\mathrm{a})$ ) showed that the absorption peaks at $\delta 5.57,5.42,5.20$, and 4.85 ppm are in the region of heterotopic protons, indicating that there are at least four sugar residues in AAPS. Based on the previous studies [52], it can be predicted from the chemical shift of the protons that AAPS has an alpha glycosidic bond. Furthermore, the hydrogens on C-2 to C- 6 of glucose are found at $\delta 3.78-3.12 \mathrm{ppm}$, the resonance peak at $\delta 3.36$ ppm belongs to the signal of $\mathrm{H}-2$ on the glucuronic acid residue, and the resonance peak at $\delta 0.64$ ppm presumably represents the signal of a methyl hydrogen. In contrast to AAPS, the ${ }^{1} \mathrm{H}$ NMR spectrum of the AAPS-iron(III) complex (Figure 6(b)) showed no clear resonance absorption peaks except for the residual peak of $\mathrm{H}_{2} \mathrm{O}$ near $\delta 4.78 \mathrm{ppm}$. Similar observations have also been reported previously by Bertini et al. [53] and Wang et al. [38]. This ${ }^{1} \mathrm{H}$ NMR invisibility in AAPS-iron(III) complex could be because the ferrous metal is paramagnetic and interferes with the magnetic environment around the ligand, consequently, affecting other peaks on the 


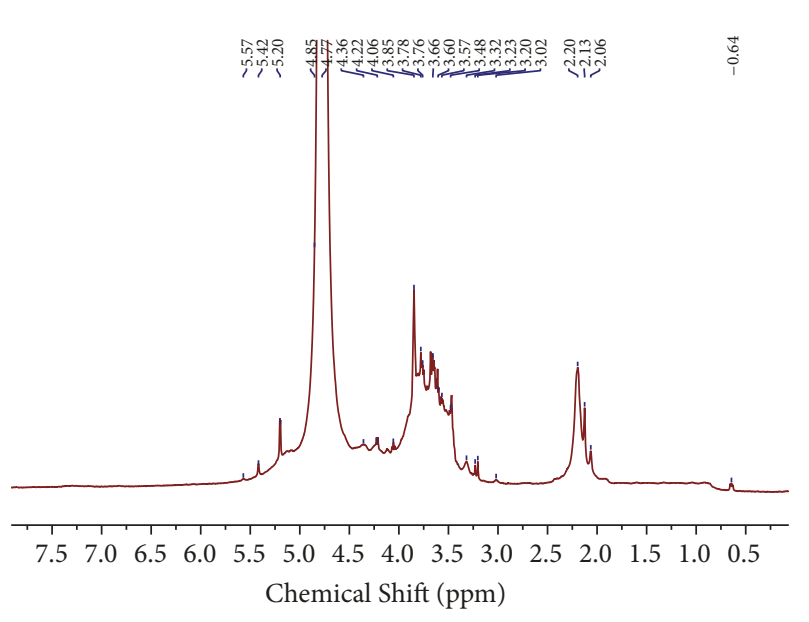

(a)

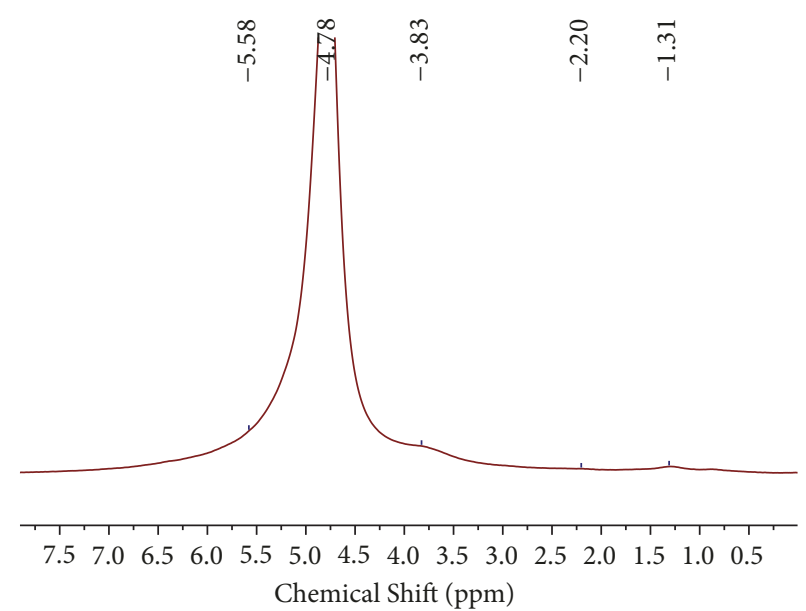

(b)

FIGURE 6: ${ }^{1} \mathrm{H}$ NMR spectra of AAPS (a) and AAPS-iron(III) complex (b).

ligand, lengthening the relaxation time, and broadening the spectral peaks. The NMR signals of the nonmetal bonded sugars were broadened and downfield-shifted (Figure 6(b)), an observation known as the Evans effect [54]. In our study, the presence of the "blind zone," i.e., the disappearance of absorption peaks caused by the complexation between AAPS and iron(III) (Figure 6(b)), suggests that the AAPS is bonded to iron(III) in the AAPS-iron(III) complex. These results further indicate that AAPS could be potentially used as an effective chelator of iron(III) for a novel human oral iron supplement.

\subsection{Iron Release In Vitro Assay of the AAPS-Iron(III) Complex.} The dissolution of the iron ions in the AAPS-iron(III) complex was investigated in an environment with a similar $\mathrm{pH}$ value to that found in human gastrointestinal digestion (Figure 7). Results showed that $53.9 \%$ of the iron ions were released in $30 \mathrm{~min}$ after the AAPS-iron(III) complex was dissolved in simulated gastric juice. A total of $76.7 \%$ and $83.1 \%$ of the iron ions were released in $60 \mathrm{~min}$ and 90 min, respectively. The relative release of iron ions in the AAPS-iron(III) complex was nearly complete in $120 \mathrm{~min}$ with $86.7 \%$ of the iron ions released. Upon transferring to an artificial intestinal juice, the amount of iron released from the AAPS-iron(III) complex increased to $93.1 \%$ in $3 \mathrm{~h}$, indicating that the AAPS-iron(III) complex exhibits higher water solubility in the environment of a gastrointestinal tract and therefore showing higher bioavailability, which is beneficial for increasing iron absorption. The high bioavailability was also reported in previous studies using in vitro simulating digestive experiments $[17,37]$ where comparable amount of iron of $87.42 \%$ and $91.74 \%$ released in $5 \mathrm{~h}$ in the AAPS-iron(III) complexes in Grifola frondosa and Astragalus membranaceus, respectively. These results demonstrate that the AAPS-iron(III) complex could be potentially an efficient candidate for iron supplementation in the treatment of iron deficiency anemia.

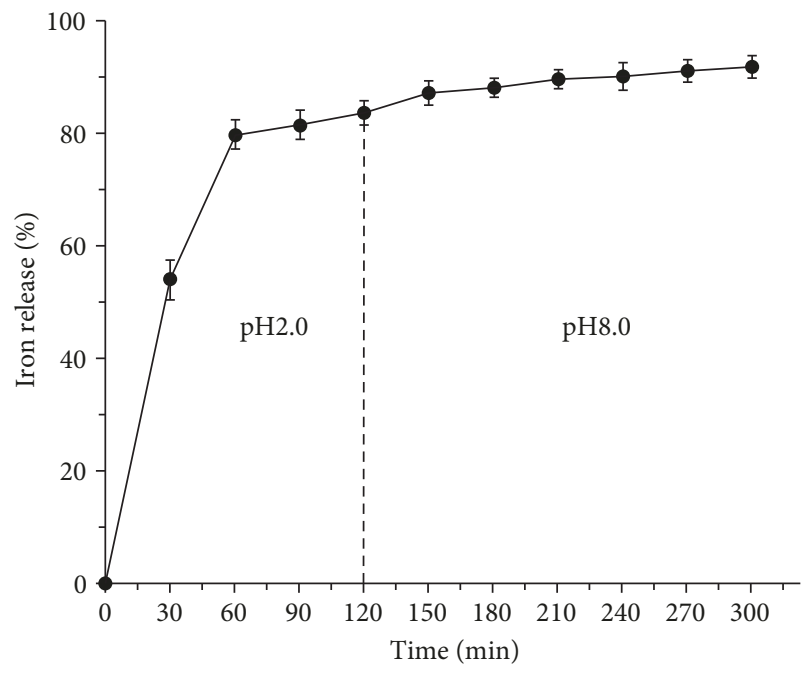

FIGURE 7: Iron release from the AAPS-iron(III) complex in artificial gastric juice ( $\mathrm{pH} 2.0)$ and artificial intestinal juice ( $\mathrm{pH} 8.0$ ).

\subsection{Antioxidant Activities of the AAPS-Iron(III) Complex}

3.4.1. DPPH Radical Scavenging Activity. The DPPH radical scavenging activity is generally used as one of the indicators to evaluate the antioxidant activity of biochemical compounds. When DPPH radicals react with antioxidants, its color changes from dark purple to bright yellow. The DPPH radical scavenging activity of the substance can be determined by measuring the absorbance at $517 \mathrm{~nm}$. Decreased absorbance at $517 \mathrm{~nm}$ indicates strong antioxidant capacity in the sample and high DPPH radical scavenging activity [55]. In our study, both AAPS and the AAPS-iron(III) complex showed strong and concentration-dependent DPPH radical scavenging activities (Figure 8). As the concentrations of the compounds increase, the corresponding DPPH radical 


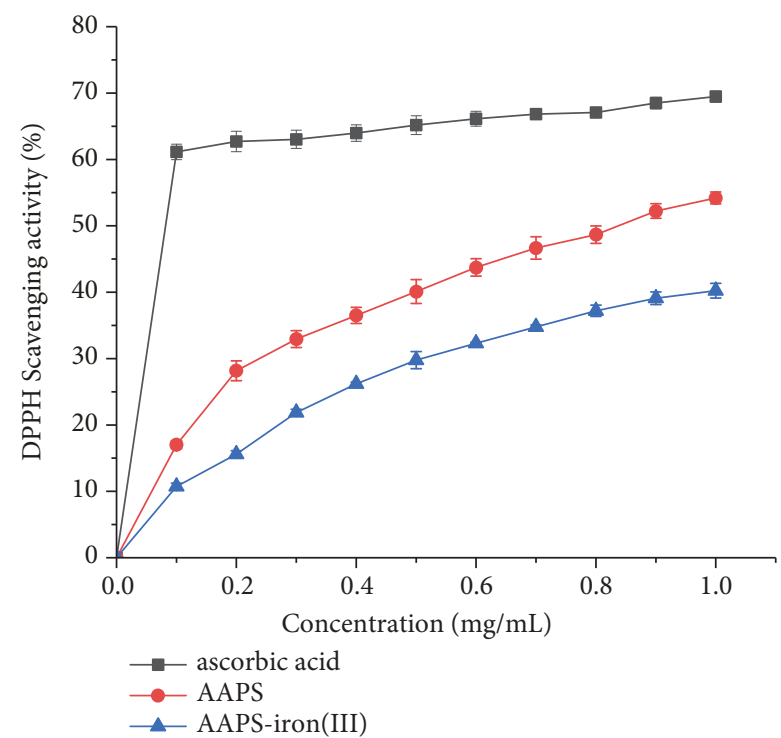

FIGURE 8: DPPH radical scavenging activity of AAPS, AAPSiron(III) complex, and ascorbic acid.

scavenging rates increase gradually, showing the solubility dependence at a given concentration. At $1.0 \mathrm{mg} / \mathrm{mL}$ (the highest concentration of the samples tested in our study), the DPPH radical scavenging activities of AAPS and the AAPS-iron(III) complex reached their highest rates of 53.8\% and $39.5 \%$, respectively. The EC50 values of ascorbic acid, AAPS, and AAPS-iron(III) complex were $0.057 \mathrm{mg} / \mathrm{mL}$, $0.190 \mathrm{mg} / \mathrm{mL}$, and $0.272 \mathrm{mg} / \mathrm{mL}$, respectively. In our study, the polysaccharide solution showed high viscosity with the concentration of the polysaccharide solution higher than $1 \mathrm{mg} / \mathrm{mL}$, significantly affecting the results of the in vitro antioxidant experiments by causing unpredictable readings of the measurements. Therefore, the highest concentration was set up at $1 \mathrm{mg} / \mathrm{mL}$ as reported in the previous studies $[26,56]$. Furthermore, it was observed from the antioxidant experiments in our study that the AAPS-iron(III) complex clearly obtained the antioxidant capability of the polysaccharide with evident trend of concentration dependence at 1 $\mathrm{mg} / \mathrm{mL}$ (Figures 8-10), even though the trend of antioxidant results could potentially continue to rise if the concentrations increased. As having antioxidant capacity is often a desirable feature for food and nutritional supplements, these antioxidant activities observed in our study suggest the additional benefits of the AAPS-iron(III) complex over many other typical but nonantioxidant iron supplements, such as the inorganic ferrous sulfate and ferrous fumarate.

3.4.2. ABTS Radical Scavenging Activity. ABTS is shown to react with $\mathrm{K}_{2} \mathrm{~S}_{2} \mathrm{O}_{8}$ to form stable cationic free radicals with an evident absorption peak at $734 \mathrm{~nm}$, while antioxidants effectively inhibit the cationic free radicals, resulting in the decreased absorbance at $734 \mathrm{~nm}$ [33]. In our study, the ABTS radical scavenging activities of AAPS and the AAPS-iron(III) complex exhibit a concentration-dependent trend (Figure 9) similar to that of their DPPH radical scavenging activities

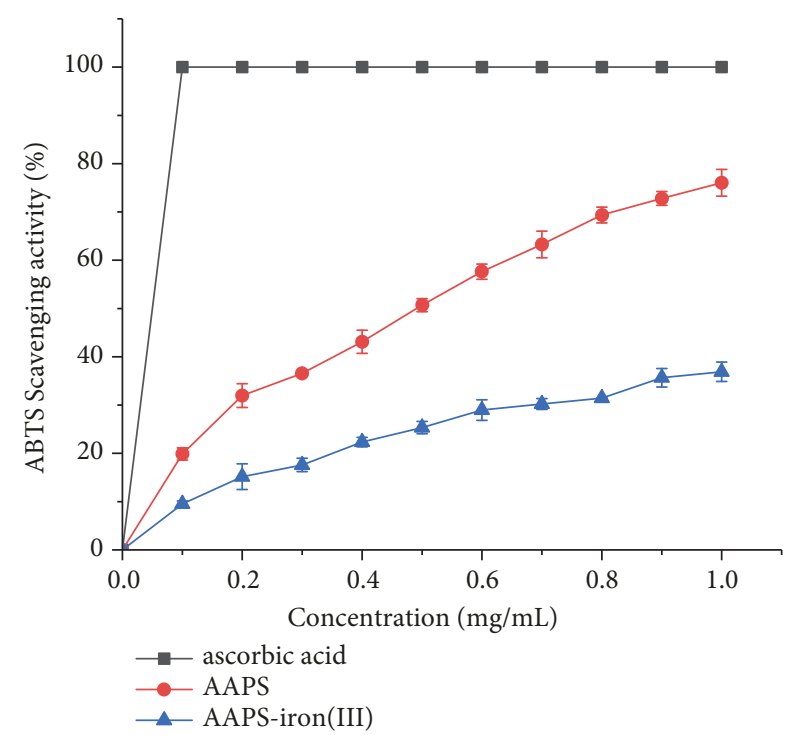

FIGURE 9: ABTS radical scavenging activity of AAPS, AAPSiron(III) complex, and ascorbic acid.

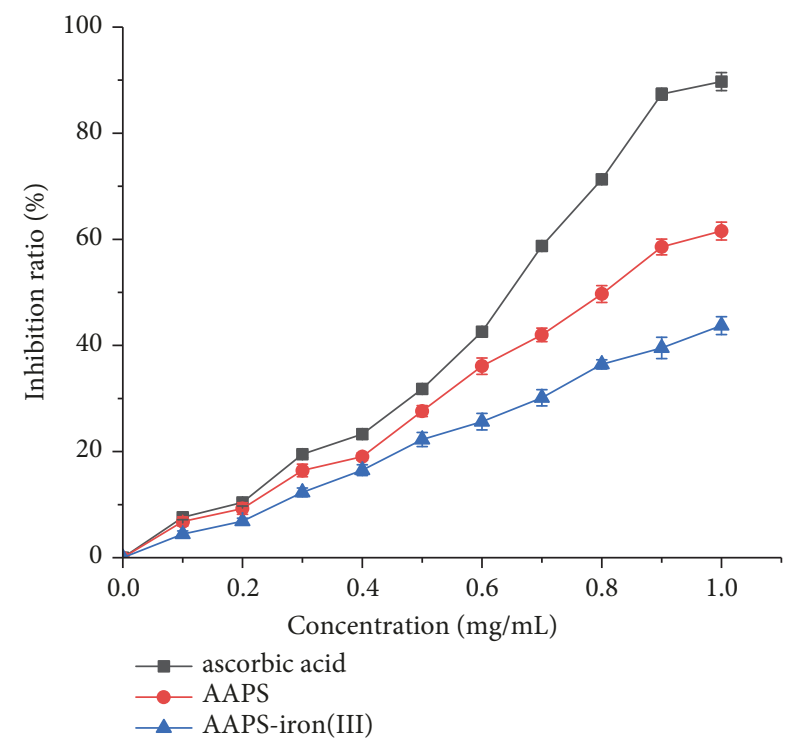

FIGURE 10: Lipid peroxidation inhibition activity of AAPS, AAPSiron(III) complex, and ascorbic acid.

(Figure 8). At the concentration of $1.0 \mathrm{mg} / \mathrm{mL}$, the ABTS free radical scavenging activity of AAPS-iron(III) and AAPS reached $35.9 \%$ and $74.8 \%$, respectively. The EC50 values of ascorbic acid, AAPS, and AAPS-iron(III) complex were $0.050 \mathrm{mg} / \mathrm{mL}, 0.322 \mathrm{mg} / \mathrm{mL}$, and $0.318 \mathrm{mg} / \mathrm{mL}$, respectively. Similar results were also reported in a recent study [26], where the antioxidant activities in the Flammulina velutipes polysaccharides-iron(III) complex were concentrationdependent and were also lower than those in their polysaccharides. These results show that the AAPS-iron(III) complex demonstrates more health benefits in comparison to the traditional iron supplements with no antioxidant capacity. 
3.4.3. Inhibition Assay on Liver Lipid Peroxidation. Iron ions catalyze the production of endogenous free radicals in the body, leading to lipid peroxidation in the cell membranes, subsequently causing cytotoxicity and damage to the biological systems [57]. In general, the increased amount of iron in body provided by the traditional iron supplements damages the biological systems. In our study, the AAPS-iron(III) complex showed a concentration-dependent inhibitory activity on liver lipid peroxidation (Figure 10). At the concentration of $1.0 \mathrm{mg} / \mathrm{mL}$, the inhibition rate of the AAPS-iron(III) complex on liver lipid peroxidation reached its highest at $43.1 \%$. The EC50 values of ascorbic acid, AAPS, and AAPS-iron(III) complex were $0.614 \mathrm{mg} / \mathrm{mL}, 0.537 \mathrm{mg} / \mathrm{mL}$, and $0.493 \mathrm{mg} / \mathrm{mL}$, respectively. Zhang et al. [58] previously reported that the polysaccharide-zinc inclusion complex in Dioscorea opposite could significantly reduce the MDA contents and increase the activities of both the superoxide dismutase (SOD) and the total antioxidant capacity (T-AOC) in rats, demonstrating that the oral administration of polysaccharide-zinc could suppress the oxidant stress in liver of rats. These results demonstrate that, due to its low oxidative toxicity, the AAPSiron(III) complex could be consumed at higher dosage levels than other traditional supplements such as ferrous sulfate without causing the side effects. With the intake of traditional iron supplements in the treatment of patients with iron deficiency anemia, the patients would show the rapid increase of iron levels in body to cause the lipid oxidative stress, resulting in a wide range of side effects in patients such as diarrhea, nausea, or vomiting. The antioxidant activity of the AAPS-iron(III) complex could inhibit the lipid oxidative stress caused by iron intake in patients and reduce the side effects occurring during the treatment. Furthermore, in comparison to the traditional iron supplements, more iron could be absorbed and the treatment cycle could be shortened in patients treated with AAPS-iron(III) complex. Moreover, the antioxidant activities of the polysaccharide retained by the AAPS-iron(III) complex could also have other positive effects on the patients, such as the enhancement of the antioxidation and immunity. Therefore, the AAPS-iron(III) complex has showed the promising potential to be the novel type of iron supplements in the treatment of patients with iron deficiency anemia.

\subsection{Antianemia Function Test of the AAPS-Iron(III) Complex.} The results of the antianemia tests showed that the AAPSiron (III) complex demonstrated a high efficiency on iron deficiency anemia (Table 1). For example, the increase of body weight in the MC group of the model rats of iron deficiency anemia is significantly larger than that in $\mathrm{BC}$ group ( $\mathrm{p}<0.05)$, while, in 35 days, the increase of body weight in both $\mathrm{HI}$ and $\mathrm{PC}$ groups was much larger than that in the MC group $(\mathrm{p}<0.01)$. Furthermore, many of the blood parameters in the MC group were significantly lower than those in the BC group $(p<0.05)$. The amount of FP in the $\mathrm{MC}$ group was significantly larger than that in the $\mathrm{BC}$ group $(\mathrm{p}<0.01)$, indicating that the rats in the MC group were iron deficient and in line with the characteristics of iron deficiency anemia. Although many of the values of the blood parameters increased and the amount of FP decreased in the LW group in comparison to the MC group, these variations were not statistically significant. Similarly, many of the values of the blood parameters increased and the amount of FP decreased in the MI group in comparison to the MC group; however, only the variations in FP and HCT were statistically significant $(\mathrm{p}<0.05)$. Furthermore, the amount of FP in both the HI and MI groups was significantly lower than that in the MC group $(\mathrm{p}<0.05)$. In comparison to the MC group, both the $\mathrm{HI}$ and PC groups showed largely increased values in all of the blood parameters examined and statistical significance was identified in the HI group $(p<0.05)$ with similar values to those in the $B C$ group. In the HI group, the body weights of the animals increased evidently, with overall apparent improvements in behaviors, activities, and hair color. These data clearly demonstrate the significant improvement on the various blood parameters in the rats of iron deficiency anemia by the Auricularia auricula polysaccharide-iron(III) complex, consequently improving the conditions of iron deficiency. These results are in line with those in a recent study [59], where the Enteromorpha polysaccharide-iron(III) complex significantly improved the blood parameters and controlled the body weight in the rats of iron deficiency anemia and further revealed the dosage-dependent relationships with the treatment effect. The APPS-iron(III) complex shows great potential for the development of a safe and an efficient iron supplement.

\section{Conclusions}

In this study, a novel Auricularia auricula polysaccharideiron(III) complex was prepared and characterized, and the synthetic conditions were optimized. The AAPS-iron(III) complex was a reddish brown powder with an iron content of $28.4 \%$, high water solubility, and high thermal stability in the temperature range of $50-256^{\circ} \mathrm{C}$. As determined from the spectral data, the iron(III) ions in the AAPS-iron(III) complex were bound to the binding sites in the AAPS to form spatially separated iron centers on the polysaccharide backbone. The complex exhibited high digestion efficiency in vitro as well as high antioxidant activity. Therefore, the AAPS is considered potentially as a ligand for chelating iron to promote digestion and absorption, which could be a great benefit for treatment of iron deficiency anemia. Furthermore, the AAPS-iron(III) complex has the advantages of reduced side effects and oxidative stresses caused by overload of iron in comparison with other currently available iron supplements. Specifically, the Auricularia auricula AAPS-iron(III) complex significantly improved the blood parameters and body weights in the model rats of iron deficiency anemia. These results suggest that the AAPS-iron(III) complex can be potentially used as a nutritional fortifier for iron supplement in industrial processing and to assist the treatment of iron deficiency anemia.

\section{Data Availability}

The data used to support the findings of this study are available from the corresponding author upon request. 


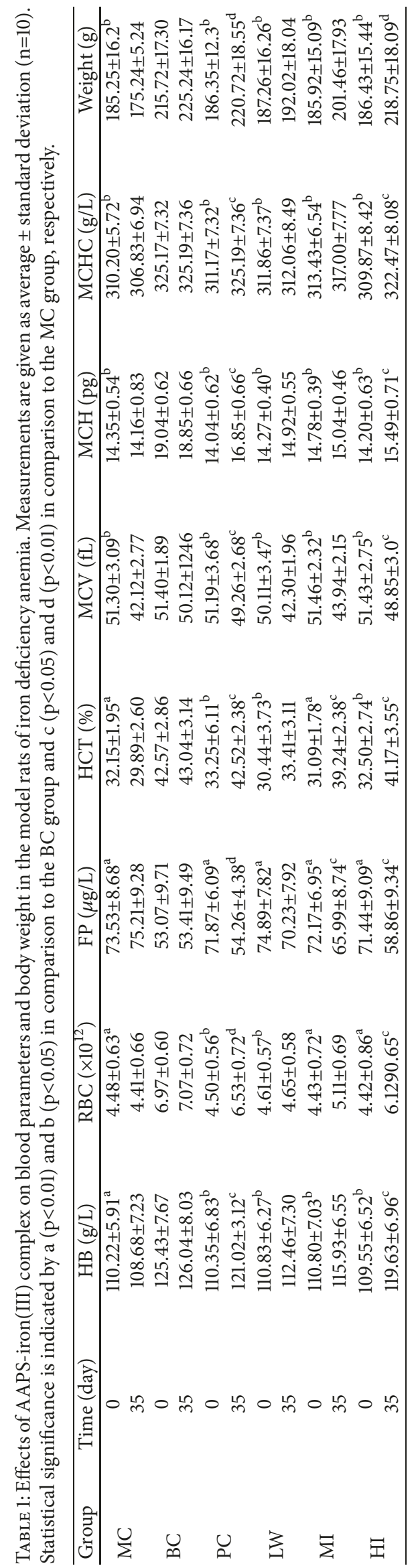




\section{Disclosure}

The funder had no role in the study design, in the collection, analysis, and interpretation of data, in the writing of the report, and in the decision to submit the paper for publication.

\section{Conflicts of Interest}

The authors declare that they have no conflicts of interest.

\section{Acknowledgments}

This work was supported by the National Science and Technology Support Program of China (Grant No. 2013BAD16B08).

\section{References}

[1] M. Tang, D. Wang, Y. Hou, P. Buchili, and L. Sun, "Preparation, characterization, bioavailability in vitro and in vivo of tea polysaccharides-iron complex," European Food Research and Technology, vol. 236, no. 2, pp. 341-350, 2013.

[2] S. C. Cottin, L. Gambling, H. E. Hayes, V. J. Stevens, and H. J. McArdle, "Pregnancy and maternal iron deficiency stimulate hepatic CRBPII expression in rats," The Journal of Nutritional Biochemistry, vol. 32, pp. 55-63, 2016.

[3] N. Al Hassand, "The prevalence of iron deficiency anemia in a Saudi University female students," Journal of Microscopy and Ultrastructure, vol. 3, no. 1, pp. 25-28, 2015.

[4] S. Denic and M. M. Agarwal, "Nutritional iron deficiency: an evolutionary perspective," Nutrition Journal, vol. 23, no. 7-8, pp. 603-614, 2007.

[5] M. J. Cancelo-Hidalgo, C. Castelo-Branco, S. Palacios et al., "Tolerability of different oral iron supplements: A systematic review," Current Medical Research and Opinion, vol. 29, no. 4, pp. 291-303, 2013.

[6] T. S. Koskenkorva-Frank, G. Weiss, W. H. Koppenol, and S. Burckhardt, "The complex interplay of iron metabolism, reactive oxygen species, and reactive nitrogen species: Insights into the potential of various iron therapies to induce oxidative and nitrosative stress," Free Radical Biology \& Medicine, vol. 65, pp. 1174-1194, 2013.

[7] A. M. G. C. Dias, A. Hussain, A. S. Marcos, and A. C. A. Roque, "A biotechnological perspective on the application of iron oxide magnetic colloids modified with polysaccharides," Biotechnology Advances, vol. 29, no. 1, pp. 142-155, 2011.

[8] X. Zhang, J. Ouyang, R. Wieczorek, and F. DeSoto, "Iron medication-induced gastric mucosal injury," Pathology Research and Practice, vol. 205, no. 8, pp. 579-581, 2009.

[9] Z.-S. Zhang, X.-M. Wang, Z.-P. Han, L. Yin, M.-X. Zhao, and S.-C. Yu, "Physicochemical properties and inhibition effect on iron deficiency anemia of a novel polysaccharide-iron complex (LPPC)," Bioorganic \& Medicinal Chemistry Letters, vol. 22, no. 1, pp. 489-492, 2012.

[10] J. Zheng, X. Yue, Z. Dai, Y. Wang, S. Liu, and X. Yan, "Novel iron-polysaccharide multilayered microcapsules for controlled insulin release," Acta Biomaterialia, vol. 5, no. 5, pp. 1499-1507, 2009.

[11] P. Laurienzo, J. C. Fernandes, S. Colliec-Jouault, and J. H. Fitton, "The use of natural polysaccharides as biomaterials," BioMed Research International, vol. 2015, Article ID 242378, 2015.
[12] A. Ahmadi, S. Z. Moghadamtousi, S. Abubakar, and K. Zandi, "Antiviral potential of algae polysaccharides isolated from marine sources: a review," BioMed Research International, vol. 2015, Article ID 825203, 10 pages, 2015.

[13] L. Xu, Y. Meng, Y. Liu et al., "A novel iron supplements preparation from Grifola frondosa polysaccharide and assessment of antioxidant, lymphocyte proliferation and complement fixing activities," International Journal of Biological Macromolecules, vol. 108, pp. 1148-1157, 2018.

[14] R. K. Saini, P. Manoj, N. P. Shetty, K. Srinivasan, and P. Giridhar, "Dietary iron supplements and Moringa oleifera leaves influence the liver hepcidin messenger RNA expression and biochemical indices of iron status in rats," Nutrition Research, vol. 34, no. 7, pp. 630-638, 2014.

[15] F. E. Viteri, E. Casanueva, M. C. Tolentino, J. Díaz-Francés, and A. B. Erazo, "Antenatal iron supplements consumed daily produce oxidative stress in contrast to weekly supplementation in Mexican non-anemic women," Reproductive Toxicology, vol. 34, no. 1, pp. 125-132, 2012.

[16] A. B. B. Torino, M. D. F. P. Gilberti, E. Da Costa, G. A. F. De Lima, and H. Z. W. Grotto, "Evaluation of red cell and reticulocyte parameters as indicative of iron deficiency in patients with anemia of chronic disease," Revista Brasileira de Hematologia e Hemoterapia, vol. 36, no. 6, pp. 424-429, 2014.

[17] Y. Xu, M. Shen, Y. Chen et al., "Optimization of the polysaccharide hydrolysate from Auricularia auricula with antioxidant activity by response surface methodology," International Journal of Biological Macromolecules, vol. 113, pp. 543-549, 2018.

[18] X.-B. Peng, Q. Li, L. Ou, L.-F. N, and K. Zeng, "GC-MS, FTIR analysis of black fungus polysaccharides and its inhibition against skin aging in mice," International Journal of Biological Macromolecules, vol. 47, pp. 304-307, 2010.

[19] Q. Wu, Z. Tan, H. Liu et al., "Chemical characterization of Auricularia auricular polysaccharides and its pharmacological effect on heart antioxidant enzyme activities and left ventricular function in aged mice," International Journal of Biological Macromolecules, vol. 46, pp. 284-288, 2010.

[20] W.-C. Zeng, Z. Zhang, H. Gao, L.-R. Jia, and W.-Y. Chen, "Characterization of antioxidant polysaccharides from Auricularia auricular using microwave-assisted extraction," Carbohydrate Polymers, vol. 89, no. 2, pp. 694-700, 2012.

[21] S. S. Ham, D. H. Kim, and D. S. Lee, "Antimutagenic effect of methyl alcohol extracts from Auricularia auricula and Gyrophora esculenta," Korean Journal of Food, Science, and Technology, vol. 29, pp. 1281-1287, 1997.

[22] S. J. Yoon, M. A. Yu, Y. R. Pyun et al., "The nontoxic mushroom Auricularia auricular contains a polysaccharide with anticoagulant activity mediated by antithrombin," Thrombosis Research, vol. 112, pp. 151-158, 2003.

[23] Z. Ma, J. Wang, L. Zhang, Y. Zhang, and K. Ding, "Evaluation of water soluble $\beta$-d-glucan from Auricularia auricular-judae as potential anti-tumor agent," Carbohydrate Polymers, vol. 80, no. 3, pp. 977-983, 2010.

[24] A. Misaki, M. Kakuta, T. Sasaki, M. Tanaka, and H. Miyaji, "Studies on interrelation of structure and antitumor effects of polysaccharides: Antitumor action of periodate-modified, branched $(1 \longrightarrow 3)$-beta-D-glucan of Auricularia auricula-judae, and other polysaccharides containing $(1 \longrightarrow 3)$-glycosidic linkages," Carbohydrate Research, vol. 92, no. 1, pp. 115-129, 1981.

[25] J. Ma, Z. Qiao, and X. Xiang, "Optimisation of extraction procedure for black fungus polysaccharides and effect of the polysaccharides on blood lipid and myocardium antioxidant 
enzymes activities," Carbohydrate Polymers, vol. 84, no. 3, pp. 1061-1068, 2011.

[26] Y.-R. Dong, S.-J. Cheng, G.-H. Qi, Z.-P. Yang, S.-Y. Yin, and G.-T. Chen, "Antimicrobial and antioxidant activities of Flammulina velutipes polysacchrides and polysacchride-iron(III) complex," Carbohydrate Polymers, vol. 161, pp. 26-32, 2017.

[27] G. Pitarresi, G. Tripodo, G. Cavallaro, F. S. Palumbo, and G. Giammona, "Inulin-iron complexes: A potential treatment of iron deficiency anaemia," European Journal of Pharmaceutics and Biopharmaceutics, vol. 68, no. 2, pp. 267-276, 2008.

[28] F. Hasan, M. Kitagawa, Y. Kumada et al., "Production kinetics of angiotensin-I converting enzyme inhibitory peptides from bonito meat in artificial gastric juice," Process Biochemistry, vol. 41, no. 3, pp. 505-511, 2006.

[29] X. Dong, C. F. Zhou, M. B. Yue, C. Z. Zhang, W. Huang, and J. H. Zhu, "New application of hierarchical zeolite in life science: Fast trapping nitrosamines in artificial gastric juice by alkalinetailored HZSM-5," Materials Letters, vol. 61, no. 14-15, pp. 31543158, 2007.

[30] H. S. AlKhatib, M. O. Taha, K. M. Aiedeh, Y. Bustanji, and B. Sweileh, "Synthesis and in vitro behavior of iron-crosslinked Nmethyl and N-benzyl hydroxamated derivatives of alginic acid as controlled release carriers," European Polymer Journal, vol. 42, no. 10, pp. 2464-2474, 2006.

[31] G.-T. Chen, X.-M. Ma, S.-T. Liu, Y.-L. Liao, and G.-Q. Zhao, "Isolation, purification and antioxidant activities of polysaccharides from Grifola frondosa," Carbohydrate Polymers, vol. 89, no. 1, pp. 61-66, 2012.

[32] X. Zhang, Q. Ban, X. Wang, and Z. Wang, "Green and efficient PEG-based ultrasonic-assisted extraction of polysaccharides from tree peony pods and the evaluation of their antioxidant activity in vitro," BioMed Research International, vol. 2018, Article ID 2121385, 7 pages, 2018.

[33] L. Liang, X. Wu, T. Zhao et al., "In vitro bioaccessibility and antioxidant activity of anthocyanins from mulberry (Morus atropurpurea Roxb.) following simulated gastro-intestinal digestion," Food Research International, vol. 46, no. 1, pp. 76-82, 2012.

[34] L. Ma, H. Chen, W. Zhu, and Z. Wang, "Effect of different drying methods on physicochemical properties and antioxidant activities of polysaccharides extracted from mushroom Inonotus obliquus," Food Research International, vol. 50, no. 2, pp. 633640, 2013.

[35] X. Li, A. Zhou, and Y. Han, "Anti-oxidation and anti-microorganism activities of purification polysaccharide from Lygodium japonicum in vitro," Carbohydrate Polymers, vol. 66, no. 1, pp. 34-42, 2006.

[36] S. Yun, T. Zhang, M. Li, B. Chen, and G. Zhao, "Proanthocyanidins inhibit iron absorption from soybean (Glycine max) seed ferritin in rats with iron deficiency anemia," Plant Foods for Human Nutrition, vol. 66, no. 3, pp. 212-217, 2011.

[37] Q. Lu, L. Xu, Y. Meng et al., "reparation and characterization of a novel Astragalus membranaceus polysaccharide-iron (III) complex," International Journal of Biological Macromolecules, vol. 93, pp. 208-216, 2016.

[38] J. Wang, H. Chen, Y. Wang, and L. Xing, "Synthesis and characterization of a new Inonotus obliquus polysaccharide-iron(III) complex," International Journal of Biological Macromolecules, vol. 75, pp. 210-217, 2015.

[39] S. B. Bothara and S. Singh, "Thermal studies on natural polysaccharide," Asian Pacific Journal of Tropical Biomedicine, vol. 2, no. 2, pp. S1031-S1035, 2012.
[40] C. Wang, Z. Chen, Y. Pan, X. Gao, and H. Chen, "Anti-diabetic effects of Inonotus obliquus polysaccharides-chromium (III) complex in type 2 diabetic mice and its sub-acute toxicity evaluation in normal mice," Food and Chemical Toxicology, vol. 108, pp. 498-509, 2017.

[41] J. Shi, C. Cheng, H. Zhao, J. Jing, N. Gong, and W. Lu, "In vivo anti-radiation activities of the Ulva pertusa polysaccharides and polysaccharide-iron(III) complex," International Journal of Biological Macromolecules, vol. 60, pp. 341-346, 2013.

[42] Ž. Mitić, G. S. Nikolić, M. Cakić, P. Premović, and L. Ilić, "FTIR spectroscopic characterization of $\mathrm{Cu}(\mathrm{II})$ coordination compounds with exopolysaccharide pullulan and its derivatives," Journal of Molecular Structure, vol. 924-926, pp. 264-273, 2009.

[43] X. Yang, M. Huang, C. Qin, B. Lv, Q. Mao, and Z. Liu, "Structural characterization and evaluation of the antioxidant activities of polysaccharides extracted from Qingzhuan brick tea," International Journal of Biological Macromolecules, vol. 101, pp. 768775, 2017.

[44] R. E. Siqueira, M. M. Andrade, D. F. Valezi et al., "EPR, FTIR and XRD investigation of soils from Paraná, Brazil," Applied Clay Science, vol. 53, no. 1, pp. 42-47, 2011.

[45] T. Yang, S. Zhang, R. Wang et al., "Polysaccharides from rhizoma panacis majoris and its anti-oxidant activity," International Journal of Biological Macromolecules, vol. 86, pp. 756-763, 2016.

[46] Y. Zhang, X. Lu, Z. Fu, Z. Wang, and J. Zhang, "Sulphated modification of a polysaccharide obtained from fresh persimmon (Diospyros kaki L.) fruit and antioxidant activities of the sulphated derivatives," Food Chemistry, vol. 127, no. 3, pp. 10841090, 2011.

[47] A. Forget, R.-A. Pique, V. Ahmadi, S. Lüdeke, and V. P. Shastri, "Mechanically tailored agarose hydrogels through molecular alloying with $\beta$-sheet polysaccharides," Macromolecular Rapid Communications, vol. 36, no. 2, pp. 196-203, 2015.

[48] K. R. Trabbic, R. A. De Silva, and P. R. Andreana, "Elucidating structural features of an entirely carbohydrate cancer vaccine construct employing circular dichroism and fluorescent labeling," MedChemComm, vol. 5, no. 8, pp. 1143-1149, 2014.

[49] E. R. Morris, D. A. Rees, and D. Thom, "Characterisation of alginate composition and block-structure by circular dichroism," Carbohydrate Research, vol. 81, no. 2, pp. 305-314, 1980.

[50] C. Zhang, M. Huang, R. Hong, and H. Chen, "Preparation of a Momordica charantia L. polysaccharide-chromium (III) complex and its anti-hyperglycemic activity in mice with streptozotocin-induced diabetes," International Journal of Biological Macromolecules, vol. 122, pp. 619-617, 2019.

[51] X. Xu, J. Li, and Y. Hu, "Polysaccharides from Inonotus obliquus sclerotia and cultured mycelia stimulate cytokine production of human peripheral blood mononuclear cells in vitro and their chemical characterization," International Immunopharmacology, vol. 21, no. 2, pp. 269-278, 2014.

[52] L. Gong, H. Zhang, Y. Niu et al., "A novel alkali extractable polysaccharide from plantago Asiatic L. seeds and its radicalscavenging and bile acid-binding activities," Journal of Agricultural and Food Chemistry, vol. 63, no. 2, pp. 569-577, 2015.

[53] I. Bertini, C. Luchinat, G. Parigi, and R. Pierattelli, "NMR spectroscopy of paramagnetic metalloproteins," ChemBioChem, vol. 6, no. 9, pp. 1536-1549, 2005.

[54] D. F. Evans, "The determination of the paramagnetic susceptibility of substances in solution by nuclear magnetic resonance," Journal of the Chemical Society (Resumed), pp. 2003-2005, 1959. 
[55] C. D. Porto, S. Calligaris, E. Celotti, and M. C. Nicoli, "Antiradical properties of commercial cognacs assessed by the DPPH. test," Journal of Agricultural and Food Chemistry, vol. 48, no. 9, pp. 4241-4245, 2000.

[56] X. Song and J. Tang, "Extraction optimization, preliminary characterization and bioactivities in vitro of Ligularia hodgsonii polysaccharides," International Journal of Molecular Sciences, vol. 17, no. 5, article no E788, 2016.

[57] B. Halliwell, J. M. C. Gutteridge, and C. E. Cross, "Free radicals, antioxidants, and human disease: where are we now?" Journal of Laboratory and Clinical Medicine, vol. 119, no. 6, pp. 598-620, 1992.

[58] Y. Zhang, M. Z. H. Khan, T. Yuan, X. Lu, Z. Du, and Y. Zhao, "Preparation and characterization of D. opposita Thunb polysaccharide-zinc inclusion complex and evaluation of antidiabetic activities," International Journal of Biological Macromolecules, vol. 121, pp. 1029-1036, 2019.

[59] J. Cui, Y. Li, P. Yu et al., "A novel low molecular weight Enteromorpha polysaccharide-iron(III) complex and its effect on rats with iron deficiency anemia (IDA)," International Journal of Biological Macromolecules, vol. 108, pp. 412-418, 2018. 


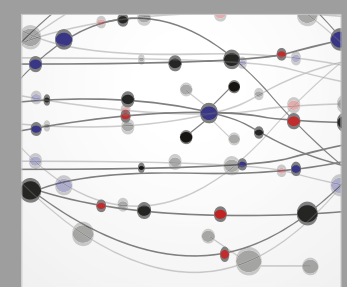

The Scientific World Journal
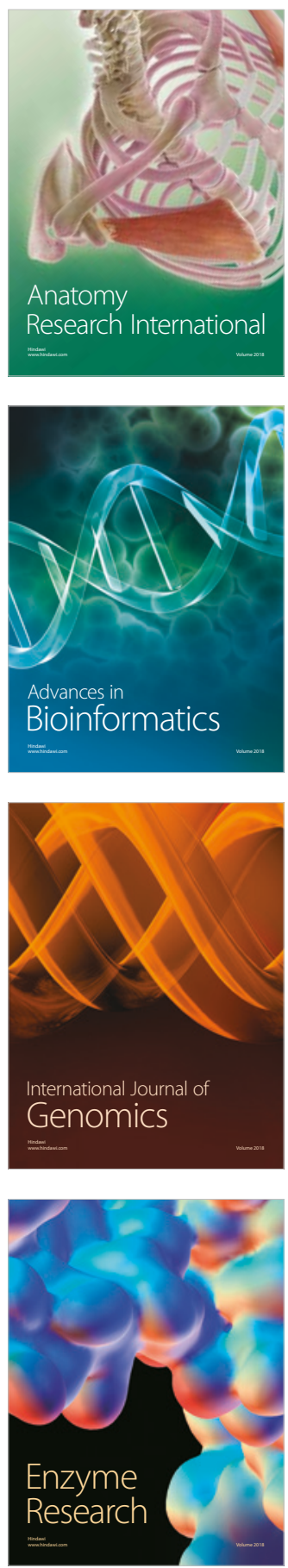
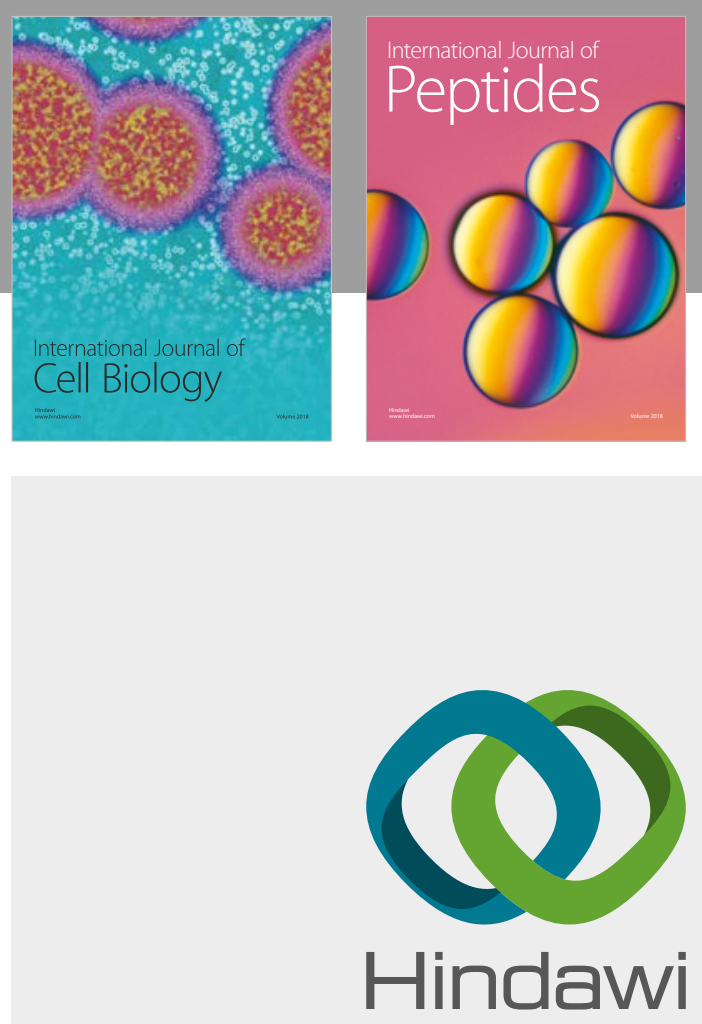

Submit your manuscripts at

www.hindawi.com
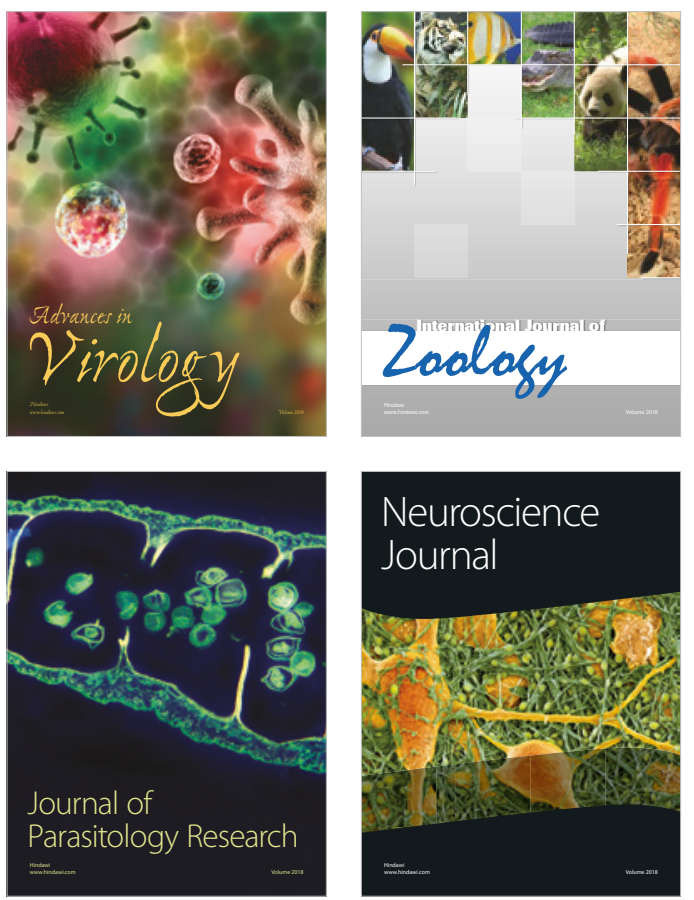
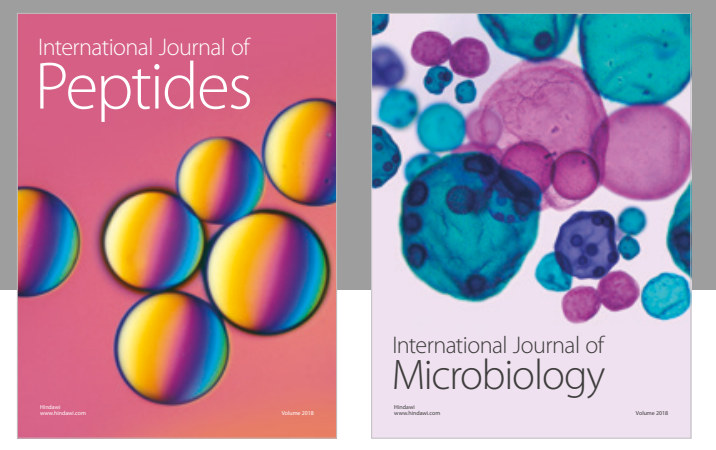

nternational Journal of Microbiology
Journal of
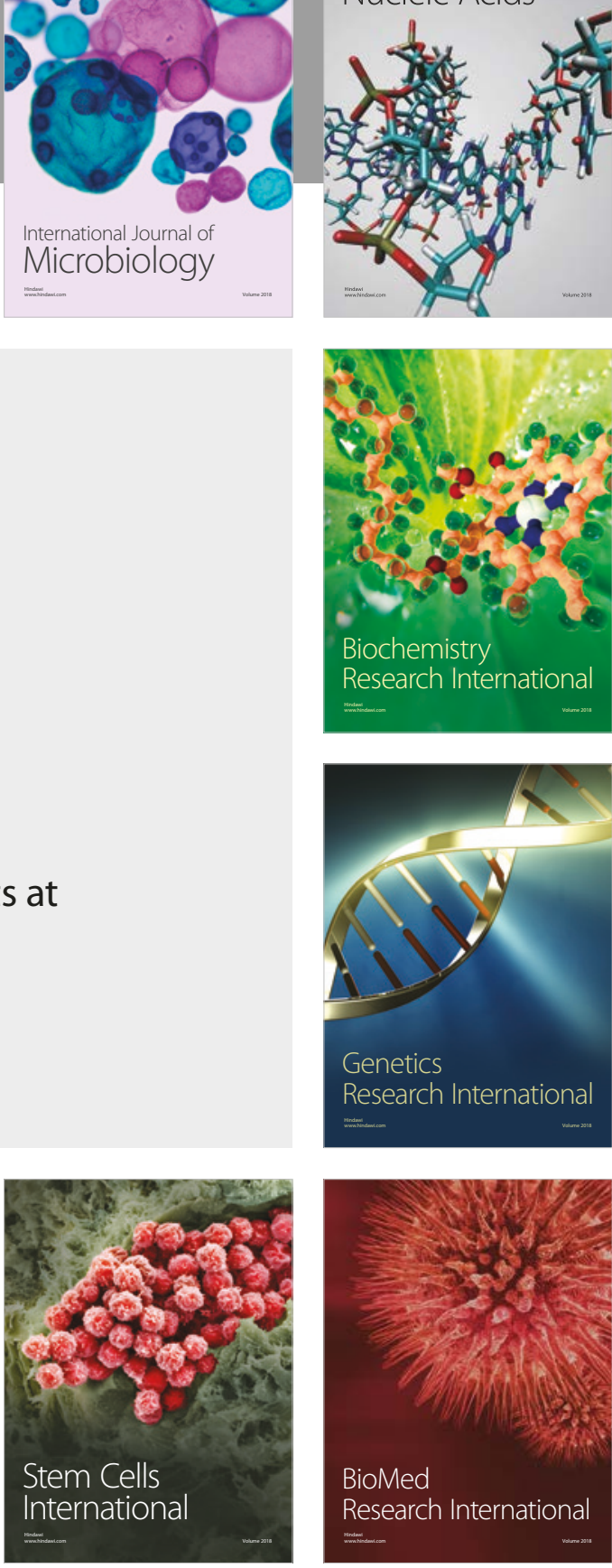
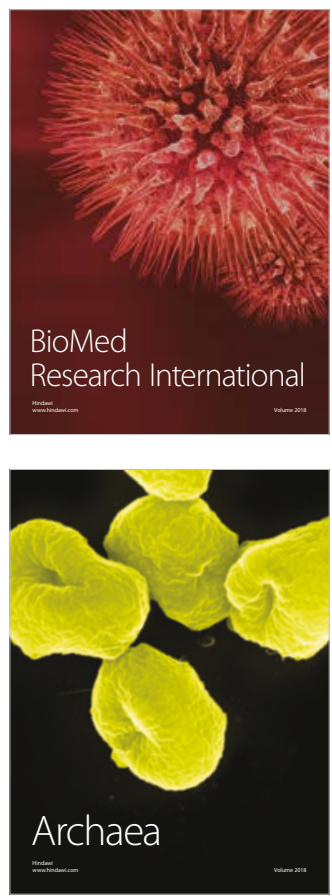